\title{
Perancangan Aplikasi Sistem Monitoring Donor Darah Pada UTD PMI Kabupaten Tasikmalaya Menggunakan Model Waterfall
}

\author{
Yusuf Sumaryana ${ }^{l}$ \\ ${ }^{1}$ Teknik Informatika, Fakultas Teknik, Universitas Perjuangan, Jalan Peta 177, Tasikmalaya \\ yusufsumaryana@unper.ac.id ${ }^{1}$
}

\begin{abstract}
INFORMASI ARTIKEL
Sejarah Artikel:

Diterima Redaksi : -

Revisi Akhir : -

Diterbitkan Online : -

Kata Kunci :

donor, aplikasi, monitoring, waterfall

Korespondensi :

Telepon / Hp : +62 85316608606

E-mail : yusufsumaryana@unper.ac.id

A B S T R A K

Berkembangnya teknologi informasi pada saat ini sangat pesat, sehingga manusia dalam mengerjakan setiap pekerjaan selalu membutuhkan komputer. Komputer memiliki peranan yang sangat vital dalam pemecahan masalah khusus dalam pengolahan data, karena komputer memiliki kecepatan tingkat akurasi yang tinggi dalam pemrosesan data, sehingga dapat mempermudah pekerjaan manusia.Adanya sistem komputer sangat membantu dalam pemecahan masalah terutama dalam hal pengolahan data. Donor darah merupakan kegiatan yang dikelola oleh Lembaga bernama Palang Merah indonesia (PMI). dalam pelaksanaan pengolahan data berbagai hal bisa terjadi. Berbagai kesalahan sangat mungkin dilakukan oleh petugas, misalnya data yang sebagian besar berupa lembaran-lembaran catatan bisa saja rusak sebelum digunakan. Maka dalam hal ini diperlukan sebuah mekanisme yang bisa mencegah terjadinya kejadian-kejadian yang akan menghambat proses monitoring.Permasalahan tersebut dapat diatasi dengan membangun sebuah sistem monitoring donor darah di Unit Transfusi Darah Palang Merah Indonesia Kab Tasikmalaya berbentuk aplikasi komputer. penelitian ini menggunakan model waterfall dalam penyusunannya. hasil dari penelitian ini berupa perancangan aplikasi monitoring donor darah PMI.
\end{abstract}

\section{PENDAHULUAN}

Bagi kelangsungan hidup manusia, darah menjadi sangat penting keberadaannya. Kecukupan stok darah harus menjadi perhatian khusus pihak terkait agar keberadaanya sensntiasa terjaga. Terjadinya kecelakaan yang menimbulkan pendarahan hebat tentunya membutuhkan ketersediaan darah yang mencukupi.

Donor darah sudah pasti berkaitan dengan transfuse darah, seseorang yang memerlukan transfuse darah sudah pasti dalam kondisi gawat secara kesehatannya yang mengancam kehidupannya, dan donor darah merupakan satusatunya cara agar tersedia darah untuk di transfusi.

Pelayanan transfusi darah adalah upaya pelayanan kesehatan yang meliputi perencanaan, pengerahandan pelestarian pendonor darah, penyediaan darah, pendistribusian darah, dan tindakan medis pemberian darah kepada pasien untuk tujuan penyembuhan penyakit dan pemulihan kesehatan[1]. Standar Pelayanan Transfusi Darah mempunyai tujuan untuk menjamin pelayanan darah yang aman, berkualitas dan dalam jumlah yang cukup[2].

Palang merah indonesia (PMI) sebagai penyelenggara resmi kegiatan donor darah di Indonesia, harus menjalankan tugas dan fungsi nya secara professional. Jumlah pendonor dan pasien penerima donor yang tidak sedikit, membuat PMI harus memiliki sistem monitoring yang lebih efektif. Selama ini proses monitoring yang dilakukan, didasarkan atas laporan yang dibuat oleh petuas PMI. Laporan yang dibuat di sajikan dalam bentuk data print out. Data pendonor, data donor darah, data permintaan darah tidak tersajikan dengan baik. tentu saja hal itu akan menjadi suatu kendala bagi seorang Kepala UTD dalam mengambil langkah yang diperlukan. Sehingga proses monitoring yang dilakukan akan berjalan tidak baik.

Berbagai kesalahan sangat mungkin dilakukan oeh petugas, misalnya data yang sebagian besar berupa lembaran-lembaran catatan bisa saja rusak sebelum digunakan. Maka dalam hal ini diperlukan sebuah mekanisme yang bisa mencegah terjadinya kejadiankejadian yang akan menghambat proses monitoring.

Beberapa penelitian terlait hali ni sudah pernah dilakukan diantaranya oleh Hamzah (Hamzah, 2015)[3], dalam penelitian ini sistem memiliki fasilitas daftar pendonor darah hidup berbasis wilayah. Utomo (Utomo, 2010) [4], dalam penelitiannya berhasil mengembangkan Perancangan Sistem Informasi Bank Darah Hidup Untuk Mempercepat Penyediaan Calon Penyumbang Darah Dengan Ketepatan Yang Tinggi (Studi di PMI Kota Samarinda) dengan sistem layanan sms untuk mendapatkan informasi ketersediaan darah.

Permasalahan tersebut dapat diatasi dengan membangun sebuah sistem informasi monitoring donor darah di Unit Transfusi Darah Palang Merah Indonesia Kab Tasikmalaya berbentuk aplikasi. Hal ini akan lebih memudahkan petugas dalam menyampaikan informasi mengenai kondisi ketersediaan darah dan monitoring kegiatan donor darah. Serta dapat membantu Kepala Seksi Donor dalam memonitoring kegiatan donor darah sehingga pengambilan keputusan yang dilakukan dapat lebih optimal. 


\section{METODOLOGI PENELITIAN}

\subsection{Metode Pengumpulan Data}

Merupakan kegiatan di awal untuk memperoleh data-data dan informasi terkait proses pengolahan dokumen yang saat ini berjalan dengan menggunakan metode pengumpulan Data. Adapun metode pengumpulan data tersebut adalah sebagai berikut:

1. Studi Literatur

Berupa pencarian sumber-sumber bacaan yang dapat menunjang penelitian yang diambil, yaitu:

2. Hasil-hasil penelitian terdahulu yang memiliki kesamaan dalam penelitian :

a. Penelitian tentang Donor Darah.

b. Penelitian tentang Sistem Informasi monitoring berbasis WEB

3. Sumber Data-data

a. Sumber Data Primer

Adalah data yang diperoleh langsung dari Instansi baik melalui pengamatan maupun pencatatan terhadap obyek penelitian.

b. Sumber Data Sekunder

Adalah data yang diambil secara tidak langsung dari objek penelitian. Data ini diperoleh dari buku-buku, dokumentasi, dan literatur-literatur.

c. Pengumpulan data-data

Berupa pengumpulan data penunjang yang dapat membantu perancangan sistem.

\subsection{Metode Pengembangan Perangkat Lunak}

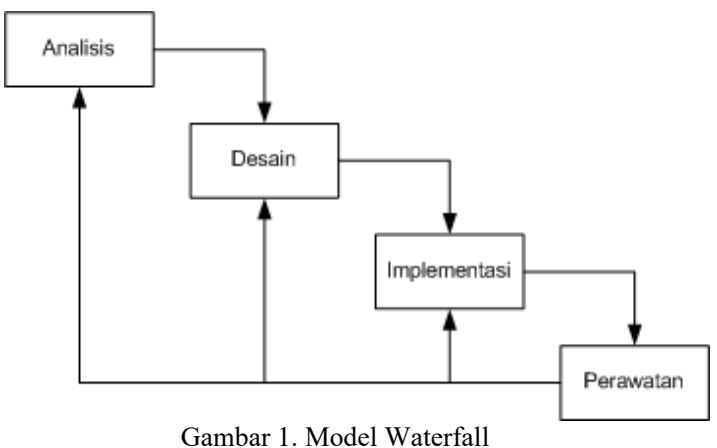

1. Analisis

Pada tahap ini yakni melakukan proses pengumpulan kebutuhan dilakukan secara intennsif untuk memspesifikasikan kebutuhan perangkat lunak agar dapat dipahami perangkat unak seperti apa yang dibutuhkan oleh user.

2. Desain

Desain perangkat lunak adalah proses multi langkah yang fokus pada desain pembuatan program perangkat lunak termasuk struktur data, arsitektur perangkat lunak, representasi antarmuka, dan prosedur pengodean. Tahap ini mentranslasi kebutuhan perangkat lunak dari tahap analisis kebutuhan ke representasi desain agar dapat diimplementasikan menjadi program pada tahap selanjutnya.
3. Implementasi

Desain harus ditranslasikan ke dalam program perangkat lunak. Hasil dari tahap ini adalah program komputer sesuai dengan desain yang telah dibuat pada tahap desain. Di tahap ini juga aplikasi yang telah dibuat diperkenalkan pada pengguna untuk dipakai.

Dalam implementasi juga dibutuhkan pemberian pelatihan pada pengguna. Hal ini dilakukan agar pengguna menjadi terbiasa dengan sistem baru yang digunakan.

4. Perawatan

Pada tahap ini perawatan pasca implementasi perlu dilakukan sebagai wujud tanggung jawab pihak pengembang kepada pengguna. Dalam proses perawatan ini pihak pengembang memberikan pelatihan pada personel yang akan ditunjuk sebagai pihak IT untuk bisa melakukan perubahan dan modifikasi terhadap sistem.

\section{HASIL DAN PEMBAHASAN}

\subsection{Analisa Sistem}

Merupakan kegiatan di awal untuk memperoleh data-data dan informasi terkait proses pengolahan dokumen yang saat ini berjalan dengan menggunakan metode pengumpulan Data.

\subsection{Kebutuhan Sistem}

a. Kebutuhan Fungsional

1. Sistem dapat melakukan update data pendonor

2. Sistem dapat melakukan update data donor darah

3. Sistem dapat melakukan update data permintaan darah perseorangan

4. Sistem dapat melakukan update data permintaan darah rumahsakat

5. Sistem dapat melakukan update data rumahsakit

6. Sistem dapat menampilkan stok darah

7. Sistem dapat menampilkan data pendonor

8. Sistem dapat menampilkan data hasil donor darah

9. Sistem dapat menampilkan data permintaan darah perseorangan

10. Sistem dapat menampilkan data permintaan darah dari rumahsakit

b. Kebutuhan Non Fungsional

1. Sistem memiliki hak akses pengguna dalam mengelola data pendonor.

2. Sistem sudah bersifat Responsive WEB sehingga dapat diakses melalui smartphone

3. Dapat diakses selama 24 jam sehari

\subsection{Perancangan Sistem}

Tahapan ini dilakukan setelah melakukan tahapan analisa berdasarkan kebutuhan sistem. Perancangan sistem terdiri dari perancangan model proses, model data dan arsitektur sistem. 
1) Model Proses

Rancangan Model Proses dibuat untuk menggambarkan proses aliran data menjadi informasi. Rancangan Model proses juga digunakan sebagai dasar dalam pengembangan sistem informasi. Rancangan Model proses juga digunakan sebagai dasar dalam pengembangan sistem.

Diagram Konteks.

Diagram konteks menurut Kristanto[6] adalah, "sebuah diagram yang menggambarkan hubungan antara entiti luar, masukan dan keluaran dari sistem". Diagram konteks yang dihasilkan dalam penelitian ini digambarkan seperti pada Gambar 2.

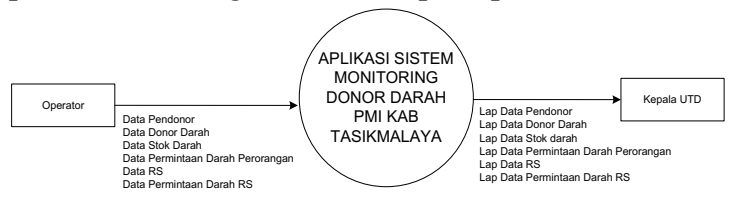

Gambar 2. diagram Konteks

Data Flow Diagram.

Menurut Kristanto[6], Data Flow Diagram (DFD) adalah suatu model logika data atau proses yang dibuat untuk menggambarkan dari mana asal data dan kemana tujuan data yang keluaran dari sistem, apabila data di simpan, proses apa yang menghasilkan data tersebut, dan interaksi antara data yang tersimpan dan proses yang dikenakan pada data tersebut. DFD yang dihasilkan dalam penelitian ini digambarkan seperti pada Gambar 3.

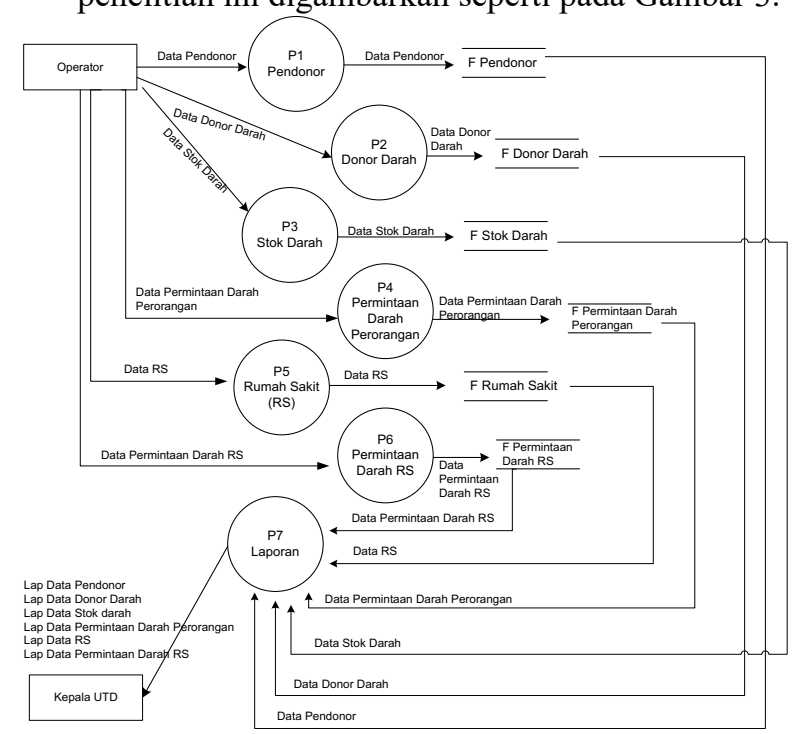

Gambar 3. Diagram Konteks

Keterangan :

P.1 Data Pendonor: Pengolahan Data Pendonor

P.2 Data Donor Darah : Pengolahan Data Penerimaan Donor Darah

P.3 Data Stok Darah : Pengolahan Stok Darah
P.4 Data Permintaan Darah Perorangan : Pengolahan Data Permintaan Darah Perorangan

P.4 Data rumah Sakit : Pengolahan Data rumah Sakit

P.6 Data Permintaan Darah RS : Pengolahan Data Permintaan Darah Perorangan

P.6 Laporan : Pengolahan laporan - laporan

2) Model Data

Model data merupakan proses yang dilakukan dalam pengembangan perangkat lunak dalam penyusunan data berupa basis data [3]. Pada penelitian ini model data dibagi menjadi 2 (dua) tahapan, yaitu : model secara logical yang digambarkan menggunakan ERD (gambar 4) dan model secara physical berupa rancangan tabel yang dibutuhkan.

ERD

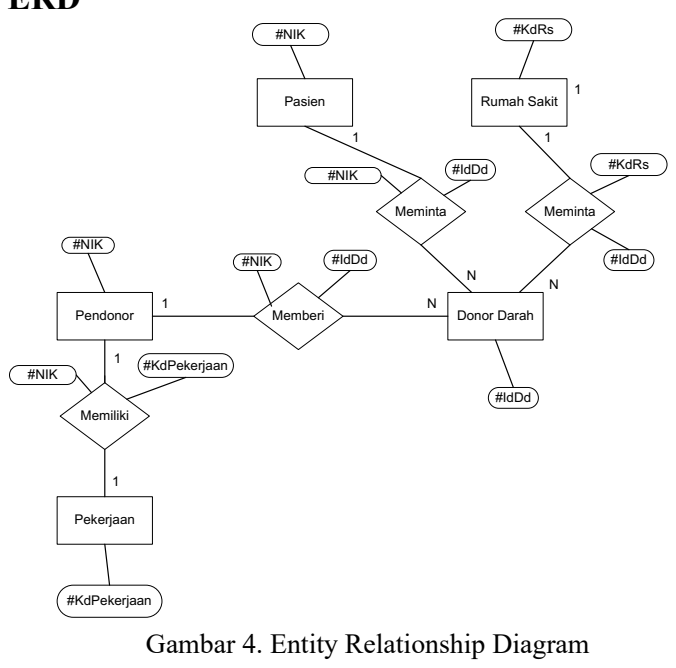

\section{Kamus Data}

Kamus data pada paerancangan yang dibuat meliputi tabel : pekerjaan, pendonor, donordarah, permintaandarahperorangan, rumahsakit, permintaandarahrs. Secara lengkap ditampilkan pada Tabel 1

Tabel 1. Kamus Data

\begin{tabular}{ll}
\multicolumn{1}{c}{ Entitas } & \multicolumn{1}{c}{ Attribut } \\
Pekerjaan & KdPekerjaan + NmPekerjaan \\
Pendonor & $\frac{\text { NIK }+ \text { Nama }+ \text { Jkelamin }+}{\text { TempatLahir }+ \text { TgLahir }+}$ \\
& AlamatRumah + RtRw + \\
& Kelurahan + Kecamatan + \\
& KodePos + KotaKab + Telepon + \\
& GolDarah + Rh + KdPekerjaan \\
IdDd + NIK + TglDonor + \\
Tempatdonor + JmlKantong + NoK \\
PermintaanDarah \\
Perorangan & IdPdp + TgPermintaan + NIK + \\
& Nama + Jkelamin + TempatLahir \\
& + TgLahir + AlamatRumah + \\
& RtRw + Kelurahan + Kecamatan \\
& + KodePos + KotaKab + Telepon \\
& + GolDarah + Rh + \\
& JmlPermintaan
\end{tabular}


RumahSakit

PermintaanDarah RS
$\underline{\mathrm{KdRs}}+\mathrm{NmRs}+$ JenisRs + Kelas + Direktur + Pemilik + Alamat + Kokab + KodePos + Telepon + Fax + Email + JenisRs + Kelas + Direktur + Pemilik + Alamat + Kokab + KodePos + Telepon + Fax + Email

$\underline{\mathrm{IdPdr}}+$ TgPermintaan $+\mathrm{KdRs}+$ $\mathrm{NIK}+\mathrm{Nama}+$ Jkelamin + TempatLahir + TgLahir + AlamatRumah + RtRw + Kelurahan + Kecamatan + KodePos + KotaKab + Telepon + GolDarah $+\mathrm{Rh}+\mathrm{JmlPermintaan}$

\section{Struktur Tabel}

Tabel yang dibutuhkan untuk pembuatan aplikasi yang dibuat sebanyak 8(delapan) tabel ditambah satu tabel untuk validasi pengguna

Tabel 2. Tabel Pekerjaan

\begin{tabular}{llcc}
$\begin{array}{lll}\text { Nama Tabel } \\
\text { Kunci Utama }\end{array}$ & $\begin{array}{l}\text { : Pekerjaan } \\
\text { : \#KdPekerjaan }\end{array}$ & & \\
\hline No & Kolom & Tipe & Ukuran \\
\hline $\mathbf{1}$ & KdPekerjaan & $\mathrm{C}$ & 1 \\
$\mathbf{2}$ & NmPekerjaan & $\mathrm{C}$ & 20 \\
\hline
\end{tabular}

Tabel 3. Tabel Pendonor

\begin{tabular}{|c|c|c|c|}
\hline $\begin{array}{l}\text { Nam } \\
\text { Kun }\end{array}$ & $\begin{array}{l}\text { : Pendonor } \\
\text { : \#NIK }\end{array}$ & & \\
\hline No & Kolom & Tipe & Ukuran \\
\hline 1 & NIK & $\mathrm{N}$ & 16 \\
\hline 2 & Nama & $\mathrm{C}$ & 30 \\
\hline 3 & Jkelamin & $\mathrm{C}$ & 9 \\
\hline 4 & TempatLahir & $\mathrm{C}$ & 20 \\
\hline 5 & TgLahir & $\mathrm{D}$ & \\
\hline 6 & AlamatRumah & $\mathrm{C}$ & 25 \\
\hline 7 & $\mathrm{RtRw}$ & $\mathrm{C}$ & 7 \\
\hline 8 & Kelurahan & $\mathrm{C}$ & 17 \\
\hline 9 & Kecamatan & $\mathrm{C}$ & 17 \\
\hline 10 & KodePos & $\mathrm{C}$ & 6 \\
\hline 11 & KotaKab & $\mathrm{C}$ & 20 \\
\hline 12 & Telepon & $\mathrm{C}$ & 15 \\
\hline 13 & GolDarah & $\mathrm{C}$ & 2 \\
\hline 14 & $\mathrm{Rh}$ & $\mathrm{C}$ & 1 \\
\hline 15 & KdPekerjaan & $\mathrm{C}$ & 1 \\
\hline
\end{tabular}

Tabel 4 Tabel Donor Darah

Nama Tabel : DonorDarah

Kunci Utama : \#IdDd

\begin{tabular}{|c|c|c|c|}
\hline No & Kolom & Tipe & Ukuran \\
\hline 1 & IdDd & $\mathrm{C}$ & 15 \\
\hline 2 & NIK & $\mathrm{C}$ & 16 \\
\hline 3 & TglDonor & D & \\
\hline
\end{tabular}

\begin{tabular}{|c|c|c|c|c|}
\hline 4 & \multicolumn{2}{|c|}{ Tempatdonor } & $\mathrm{C}$ & 40 \\
\hline 5 & \multicolumn{2}{|c|}{ JmlKantong } & $\mathrm{N}$ & \\
\hline 6 & \multicolumn{2}{|c|}{ NoKantongDarah } & $\mathrm{C}$ & 9 \\
\hline \multicolumn{5}{|c|}{ Tabel 5 Tabel Pekerjaan } \\
\hline \multicolumn{2}{|c|}{$\begin{array}{l}\text { Nama Tabel } \\
\text { Kunci Utama }\end{array}$} & \multicolumn{3}{|c|}{$\begin{array}{l}\text { : PermintaanDarahPerorangan } \\
\text { : \#IdPdp }\end{array}$} \\
\hline No & & Kolom & Tipe & Ukuran \\
\hline 1 & \multicolumn{2}{|l|}{ IdPdp } & $\mathrm{C}$ & 15 \\
\hline 2 & \multicolumn{2}{|c|}{ TgPermintaan } & $\mathrm{D}$ & \\
\hline 3 & \multicolumn{2}{|l|}{ NIK } & $\mathrm{N}$ & 16 \\
\hline 4 & \multicolumn{2}{|l|}{ Nama } & $\mathrm{C}$ & 30 \\
\hline 5 & \multicolumn{2}{|c|}{ Jkelamin } & $\mathrm{C}$ & 9 \\
\hline 6 & \multicolumn{2}{|c|}{ TempatLahir } & $\mathrm{C}$ & 20 \\
\hline 7 & \multicolumn{2}{|c|}{ TgLahir } & $\mathrm{D}$ & \\
\hline 8 & \multicolumn{2}{|c|}{ AlamatRumah } & $\mathrm{C}$ & 25 \\
\hline 9 & \multicolumn{2}{|l|}{ RtRw } & $\mathrm{C}$ & 7 \\
\hline 10 & \multicolumn{2}{|c|}{ Kelurahan } & $\mathrm{C}$ & 17 \\
\hline 11 & \multicolumn{2}{|c|}{ Kecamatan } & $\mathrm{C}$ & 17 \\
\hline 12 & \multicolumn{2}{|c|}{ KodePos } & $\mathrm{C}$ & 6 \\
\hline 13 & \multicolumn{2}{|c|}{ KotaKab } & $\mathrm{C}$ & 20 \\
\hline 14 & \multicolumn{2}{|c|}{ Telepon } & $\mathrm{C}$ & 15 \\
\hline 15 & \multicolumn{2}{|c|}{ GolDarah } & $\mathrm{C}$ & 2 \\
\hline 16 & \multicolumn{2}{|l|}{$\mathrm{Rh}$} & $\mathrm{C}$ & 1 \\
\hline 17 & \multicolumn{2}{|c|}{ KdPekerjaan } & $\mathrm{C}$ & 1 \\
\hline 18 & \multicolumn{2}{|c|}{ JmlPermintaan } & $\mathrm{N}$ & \\
\hline
\end{tabular}

Tabel 6 Tabel Rumahsakit

Nama Tabel : RumahSakit

Kunci Utama : \#KdRs

\begin{tabular}{|c|c|c|c|}
\hline No & Kolom & Tipe & Ukuran \\
\hline 1 & KdRs & $\mathrm{N}$ & 7 \\
\hline 2 & NmRs & $\mathrm{C}$ & 50 \\
\hline 3 & JenisRs & $\mathrm{C}$ & 15 \\
\hline 4 & Kelas & $\mathrm{C}$ & 1 \\
\hline 5 & Direktur & $\mathrm{C}$ & 40 \\
\hline 6 & Pemilik & $\mathrm{C}$ & 20 \\
\hline 7 & Alamat & $\mathrm{C}$ & 70 \\
\hline 8 & KotaKab & $\mathrm{C}$ & 20 \\
\hline 9 & KodePos & $\mathrm{N}$ & 6 \\
\hline 10 & Telepon & $\mathrm{C}$ & 16 \\
\hline 11 & Fax & $\mathrm{C}$ & 16 \\
\hline 12 & Email & $\mathrm{C}$ & 40 \\
\hline
\end{tabular}

Tabel 7 Permintaan Darah RS

Nama Tabel : PermintaanDarahRs

Kunci Utama : \#IdPdr

\begin{tabular}{|c|c|c|c|}
\hline No & Kolom & Tipe & Ukuran \\
\hline 1 & IdPdr & $\mathrm{C}$ & 15 \\
\hline 2 & TgPermintaan & $\mathrm{D}$ & \\
\hline 3 & KdRs & $\mathrm{C}$ & 7 \\
\hline 4 & NIK & $\mathrm{N}$ & \\
\hline 5 & Nama & $\mathrm{C}$ & 30 \\
\hline 6 & Jkelamin & $\mathrm{C}$ & 9 \\
\hline 7 & TempatLahir & $\mathrm{C}$ & 20 \\
\hline
\end{tabular}




\begin{tabular}{cllc}
\hline $\mathbf{8}$ & TgLahir & $\mathrm{D}$ & \\
$\mathbf{9}$ & AlamatRumah & $\mathrm{C}$ & 25 \\
$\mathbf{1 0}$ & RtRw & $\mathrm{C}$ & 7 \\
$\mathbf{1 1}$ & Kelurahan & $\mathrm{C}$ & 17 \\
$\mathbf{1 2}$ & Kecamatan & $\mathrm{C}$ & 17 \\
$\mathbf{1 3}$ & KodePos & $\mathrm{C}$ & 6 \\
$\mathbf{1 4}$ & KotaKab & $\mathrm{C}$ & 20 \\
$\mathbf{1 5}$ & Telepon & $\mathrm{C}$ & 15 \\
$\mathbf{1 6}$ & GolDarah & $\mathrm{C}$ & 2 \\
$\mathbf{1 7}$ & Rh & $\mathrm{C}$ & 1 \\
$\mathbf{1 8}$ & JmlPermintaan & $\mathrm{N}$ & \\
\hline
\end{tabular}

Tabel 8 Tabel Penyerahan darah Perorangan

\begin{tabular}{|c|c|c|c|c|}
\hline \multicolumn{2}{|c|}{$\begin{array}{l}\text { Nama Tabel } \\
\text { Kunci Utama }\end{array}$} & \multicolumn{3}{|c|}{$\begin{array}{l}\text { : PenyerahanDarahPerorangan } \\
\text { : \#IdSdp }\end{array}$} \\
\hline No & & Kolom & Tipe & Ukuran \\
\hline 1 & IdSdp & & $\mathrm{C}$ & 16 \\
\hline 2 & IdPdp & & $\mathrm{C}$ & 15 \\
\hline 3 & TgPeny & rahan & D & \\
\hline 4 & NoKan & ngDarah & $\mathrm{N}$ & \\
\hline
\end{tabular}

Tabel 9 Tabel Penyerahan darah Rumahsakit

\begin{tabular}{|c|c|c|c|c|}
\hline \multicolumn{2}{|c|}{$\begin{array}{l}\text { Nama Tabel } \\
\text { Kunci Utama }\end{array}$} & \multicolumn{3}{|c|}{$\begin{array}{l}\text { : PenyerahanDarahRumahsakit } \\
\text { : \#IdSdp }\end{array}$} \\
\hline No & & Kolom & Tipe & Ukuran \\
\hline 1 & IdSdr & & $\mathrm{C}$ & 16 \\
\hline 2 & IdPdr & & $\mathrm{C}$ & 15 \\
\hline 3 & TgPeny & rahan & D & \\
\hline 4 & NoKan & ngDarah & $\mathrm{N}$ & \\
\hline
\end{tabular}

Tabel 10 Tabel Pengguna

\begin{tabular}{|c|c|c|c|c|}
\hline \multicolumn{2}{|c|}{$\begin{array}{l}\text { Nama Tabel } \\
\text { Kunci Utama }\end{array}$} & \multicolumn{3}{|c|}{$\begin{array}{l}\text { : pengguna } \\
\text { : \#nmpengguna }\end{array}$} \\
\hline No & & Kolom & Tipe & Ukuran \\
\hline 1 & \multicolumn{2}{|c|}{ nmpengguna } & $\mathrm{C}$ & 30 \\
\hline 2 & \multicolumn{2}{|c|}{ katakunci } & $\mathrm{C}$ & 30 \\
\hline 3 & \multicolumn{2}{|l|}{ level } & $\mathrm{C}$ & 1 \\
\hline
\end{tabular}

3) Arsitektur Sistem

Perancangan arsitektur sistem yang dibuat adalah seperti pada gambar 5 .

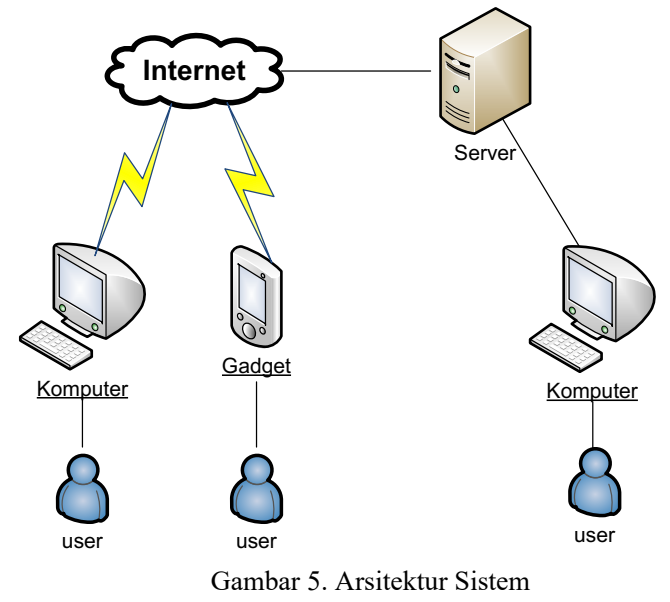

\section{KESIMPULAN}

Permasalahan pencatatan donor darah diatasi dengan membangun sebuah sistem informasi monitoring donor darah di Unit Transfusi Darah Palang Merah Indonesia Kab Tasikmalaya berbentuk aplikasi yang telah dibuat dan berjalan sesuai dengan kondisi riil di lapangan. Hal ini memudahkan petugas dalam menyampaikan informasi mengenai kondisi ketersediaan darah dan monitoring kegiatan donor darah. Serta membantu Kepala Seksi Donor dalam memonitoring kegiatan donor darah sehingga pengambilan keputusan yang dilakukan dapat lebih optimal.

\section{DAFTAR PUSTAKA}

[1] P. M. K. R. I. N. 7 t. 2011, "peraturan menteri kesehatan republik indonesia nomor 7 tahun 2011 tentang pelayanan darah," permenkes, 2015.

[2] P. M. K. R. I. N. 91 t. 2015, "peraturan menteri kesehatan republik indonesia nomor 91 tahun 2015 tentang standar pelayanan transfusi darah," permenkes, vol. 49, no. 23-6, 2015.

[3] Hamzah, "Analisa dan rancang sistem informasi ketersediaan donor darah hidup," J. Ilmu Teknol. Inf. Terap., vol. 1, no. 2, pp. 15-20, 2015.

[4] K. B. Utomo, "Perancangan Sistem Informasi Bank Darah Hidup Untuk Mempercepat Penyediaan Calon Penyumbang Darah Dengan Ketepatan Yang Tinggi (Studi di PMI Kota Samarinda),” J. Inform. Mulawarman, vol. 5, no. 2, 2010.

[5] T. H. Hari, "Perbandingan Waterfall Model Dan Metode Generik Dalam Manajemen Proyek Perangkat Lunak Sistem Pengelolaan Dana Bantuan Operasional Sekolah (BOS) (Studi Kasus: Man 1 Kota Lhokseumawe)," J. Ecotipe, vol. 3, no. 1, 2016.

[6] V. Feladi and C. Lesmana, “Aplikasi Pengolah Data Pada LPK (Lembaga Pelatihan Kursus) Sheza Komputer Pontianak," J. Edukasi dan Penelit. Inform., vol. 4, no. 1, p. 60, 2018. 